\title{
Studi Sebaran Klorofil-a Secara Horizontal di Perairan Muara Sungai Silugonggo Kecamatan Batangan, Pati
}

\author{
Greenaty Hidayah, Sri Yulina Wulandari, Muhammad Zainuri \\ Program Studi Oseanografi, Fakultas Perikanan dan Ilmu Kelautan, Universitas Diponegoro \\ Kampus Tembalang, Semarang 50275 Telp/Fax. 024-7474698 \\ Email: yulinawulandari@yahoo.com
}

\begin{abstract}
Abstrak
Daerah perairan muara Sungai Silugonggo merupakan salah satu wilayah yang terletak di pesisir Laut Jawa, Kabupaten Pati. Pada daerah pesisir di wilayah perairan ini terdapat pemukiman penduduk, pertambakan dan terdapat kawasan mangrove yang merupakan sumber utama nutrien yang masuk di perairan tersebut. Kondisi ini menyebabkan wilayah perairan muara Sungai Silugonggo akan mengalami persebaran sesuai dengan dinamika oseanografi. Tujuan penelitian ini adalah mengetahui pola sebaran dan nilai kandungan klorofil-a serta mengetahui pola arus yang mempengaruhi sebaran klorofil-a secara horizontal di Perairan Muara Sungai Silugonggo, Kecamatan Batangan, Pati. Penelitian ini menggunakan data primer berupa klorofil-a, nutrien, parameter kualitas perairan, arus dan data sekunder adalah bathimetri dan pasang surut. Pengolahan data menggunakan pemodelan numerik. Hasil penelitian ini menunjukkan nilai kandungan klorofil-a berdasarkan tanggal sampling berada pada kisaran $0,4981-12,1307 \mathrm{mg} / \mathrm{m}^{3}$ dan memiliki nilai ratarata setiap pengambilan sebesar 2,5348, 3,2425 dan 3,8499 $\mathrm{mg} / \mathrm{m}^{3}$. Berdasarkan hasil pengamatan menunjukkan bahwa nilai kandungan klorofil-a secara horizontal di Perairan Muara Sungai Silugonggo lebih dipengaruhi oleh masukan dari sungai, vegetasi mangrove dan daerah pertambakan. Sebaran klorofil-a di Perairan Muara Sungai Silugonggo memiliki pola mengarah dari wilayah muara sungai ke arah laut. Persebaran klorofil-a secara horizontal dominan dipengaruhi oleh arus dengan pola mengarah dari timur laut $\left(45^{\circ}\right)$ ke arah barat daya $\left(225^{\circ}\right)$ dengan kecepatan berkisar $0,03-0,15 \mathrm{~m} / \mathrm{det}$.
\end{abstract}

Kata Kunci: Sebaran, Horizontal, Klorofil-a, Silugonggo, Fisik-Kimia Perairan

\begin{abstract}
Abstrac
Silugonggo estuary is an area located in coast of Java Sea, Pati. In the coastal region in this territorial waters, there are settlements, fish ponds and mangrove area, which is a major source of nutrients for the waters. This condition causes the territorial waters of Silugonggo River estuary will have distribution in according with the Oceanographic dynamics. The purpose of this research is to know the value and distribution pattern of chlorophll-a and figure out the pattern of currents influencing the distribution of chlorophyll-a horizontally in the waters of the Silugonggo River estuary, Batangan District, Pati. The primary data which were used in this research was chlorophyll-a, the quality of the waters, nutrients, currents and the secondary data was bathymetry and tide. Data processing used numerical modeling. The results of this research reveals the value of chlorophyll-a based on the sampling dates were in the range of 0.4981 $12.1307 \mathrm{mg} / \mathrm{m}^{3}$ and had an average rating of any taking of $2.5348,3.2425$ and $3.8499 \mathrm{mg} / \mathrm{m}^{3}$. Based on the observation indicated that the horizontal contents value of chlorophyll-a in waters of the Silugonggo River estuary was influenced by input from rivers, mangrove vegetation and fish pond areas. Distribution of chlorophyll-a in waters of the Silugonggo River estuary had a pattern leading from the mouth of the River towards the sea. The horizontal distribution of chlorophyll-a is more influenced by currents from the NorthEast $\left(45^{\circ}\right)$ to the South-West $\left(225^{\circ}\right)$ with range velocity $0,03-0,15 \mathrm{~m} / \mathrm{s}$.
\end{abstract}

Keywords: Distribution, Horizontal, Chlorophyll-a, Silugonggo, Physical-Chemical Waters

\section{PENDAHULUAN}

Wilayah perairan pesisir pantai Utara Jawa dikenal sebagai daerah yang produktif (Saraswati,
2004). Hal ini dikarenakan daerah tersebut merupakan perairan yang memiliki banyak muara sungai dengan kandungan bahan organik yang
*) Corresponding author

buloma.undip@gmail.com http://ejournal.undip.ac.id/index.php/buloma

Diterima/Received : 12-01-2016

Disetujui/Accepted : 17-03-2016 
cukup tinggi. Zainuri (2010) menjelaskan, bahwa produktivitas perairan di pantai utara Jawa cukup tinggi, karena keberadaan ekosistem hutan mangrove, muara sungai, terumbu karang, pertambakan dan padang lamun. Ekosistemekosistem tersebut saling terkait, yaitu terjadi pertukaran unsur nutrien antar ekosistem sehingga dapat saling mensuplai untuk menunjang kehidupannya. Persebaran unsur nutrien pada wilayah pesisir dan muara terkait pula dengan proses fisika dan kimia perairan yang terjadi di wilayah tersebut.

Dinyatakan oleh Effendi (2003), bahwa proses fisika di wilayah pesisir meliputi arus, gelombang, pasang surut, sedangkan proses kimia terdiri dari BOD (biological oxygen demand), COD (chemical oxygen demand) dan DO (dissolved oxygen). Proses-proses tersebut secara bersamaan terjadi dan mengakibatkan peningkatan kandungan nutrien (nitrat dan ortofosfat) di dalam perairan, yang pada tahap selanjutnya akan digunakan untuk proses fotosintesis. Sumber nutrien (nitrat dan ortofosfat) secara alamiah berasal dari perairan itu sendiri melalui proses-proses penguraian pelapukan ataupun dekomposisi tumbuhtumbuhan, sisa organisme mati dan buangan limbah baik limbah daratan seperti domestik, industri, pertanian dan limbah peternakan. Oleh adanya arus yang merupakan salah satu parameter oseanografi menyebabkan nutrien dan klorofil-a akan mengalami persebaran sesuai dengan pergerakan massa air yang mempengaruhi. Umumnya, kandungan nutrien yang tinggi di daerah pesisir akan mempengaruhi tingginya sebaran klorofil-a di perairan. Oleh karena itu diperlukan pengamatan tentang persebaran klorofil-a terkait dengan faktor fisika dan kimia perairan di wilayah perairan muara Sungai Silugonggo.

Tujuan dari penelitian ini adalah untuk mengetahui pola sebaran dan nilai kandungan klorofil-a serta mengetahui pola arus yang mempengaruhi sebaran klorofil-a secara horizontal di Perairan Muara Sungai Silugonggo, Kecamatan Batangan, Pati.

\section{MATERI DAN METODE}

Materi penelitian berupa sampel air yang diambil dari Perairan Muara Sungai Silugonggo, yang selanjutnya dibawa ke laboratorium untuk dianalisis. Pengambilan sampel air dilakukan sebanyak tiga kali dengan waktu (hari) yang berbeda (29 Maret, 12 April dan 26 April 2015). Sebagai data primer adalah data laboratorium klorofil-a, nitrat, ortofosfat, kualitas perairan dan arus. Adapun data sekunder adalah data yang diperoleh dari instansi terkait yang meliputi Peta Lingkungan Perairan Indonesia (LPI) Jawa Tengah Tahun 2004 skala 1:500.000 publikasi Dinas Hidro-Oseanografi TNI-AL, Peta Rupa Bumi Indonesia (RBI) Kabupaten Pati Tahun 1999 skala 1:25.000, lembar 1509-132 publikasi BAKOSURTANAL serta Data peramalan pasang surut yang diperoleh dari Dinas HidroOseanografi (DISHIDROS) TNI AL.

Metode yang digunakan dalam penelitian ini adalah metode kuantitatif. Menurut Sugiyono (2014), metode kuantitatif memenuhi kaidahkaidah ilmiah yaitu konkret, obyektif, terukur, rasional, sistematis. Adapun penentuan lokasi (stasiun) pengukuran dan pengamatan dilakukan dengan metode purposive (purposive sampling method). Menurut Damaianto et. al. (2014), metode purposif adalah metode penentuan lokasi pengambilan sampel berdasarkan pertimbangan pertimbangan lokasi dan waktu. Pengambilan sampel dilakukan pada 8 stasiun pengamatan dengan mempertimbangkan 4 karakteristik perairan, yaitu mewakili daerah muara sungai, vegetasi mangrove, daerah pertambakan dan laut agak dalam. Batasan penelitian ini adalah pengaruh hidrodinamika ditinjau dari arus pasang surut.

Pengambilan sampel air laut (bagian permukaan) dilakukan pada pukul $08.00-10.00$ WIB saat perairan dalam kondisi surut menuju pasang. Dalam penelitian ini, parameter kualitas perairan yang diukur meliputi suhu, $\mathrm{pH}, \mathrm{DO}$, salinitas dan kecerahan dilakukan dengan menggunakan water quality checker, DO meter, refraktometer dan sechidisk. Adapun pengukuran arus dilakukan dengan menggunakan pendekatan Lagrangian, yaitu mengamati gerakan massa air permukaan dalam rentang waktu tertentu menggunakan pelampung (alat bola duga). Bola duga terdiri dari kipas, bola pelampung, dan tali (panjang 5 meter) yang di lepas ke perairan. Kecepatan dan arah arus akan diketahui dengan melihat arah bola pelampung dengan kompas tembak dan menghitung waktu yang diperlukan tali pelampung hingga tegang. Rumus untuk menghitung kecepatan arus yaitu:

$$
\text { Kecepatan arus }=\frac{\text { panjang tali }}{\text { lama pengamatan }} \text { meter } / \text { detik }
$$

Analisis klorofil-a menggunakan metode spektrofotometer (Richards and Thompson, 1952 dalam Riyono, 2006). Sampel air disaring dengan 
menggunakan kertas saring Millipore Filter jenis HAWP, kemudian direndam dalam aseton $90 \%$ untuk ekstraksi kandungan klorofil-a. Sampel dimasukkan kedalam tabung centrifuge selama 30 - 45 menit agar terpisah antara hasil ekstraksi kandungan klorofil-a yang berwarna bening atau hijau dengan kertas saring yang larut dalam aseton. Selanjutnya mencari nilai absorbansi sampel dengan spektrofotometer. Konsentrasi klorofil-a dihitung dengan menggunakan rumus (Strickland and Thompson, 1968 dalam Riyono, 2006) :

Chl- $a=11,6 \mathrm{E} 665-1,31 \mathrm{E} 645-1,41 \mathrm{E} 630 \ldots . . .(2)$

keterangan:

Chl-a : kandungan klorofil-a $\left(\mathrm{mg} / \mathrm{m}^{3}\right)$

E : penyerapan pada panjang gelombang yang bersangkutan

Untuk menghitung kadar klorofil pada sampel air laut dalam satuan $\mathrm{mg} / \mathrm{m}^{3}$ maka nilai di atas dikalikan dengan faktor $(\mathrm{k})$ berdasarkan jumlah sampel air yang disaring.

Faktor :

$$
k=\frac{V a}{V s x d}
$$

keterangan :

$\mathrm{Va}=$ volume ekstrak $(\mathrm{ml})$

$\mathrm{Vs} \quad=$ volume air laut yang disaring (liter)

$\mathrm{D} \quad=$ lebar kuvet, path lenght $(\mathrm{cm})$

Adapun prosedur analisa sampel nutrien sebagai variabel pendukung mengacu pada SNI 06-2480-1991 untuk nitrat dan SNI 06-6889.312005 untuk ortofosfat. Data hasil laboratorium klorofil-a digambarkan pola sebarannya dengan menggunakan software Arc GIS 10.1. Grafik tipe pasang surut dibuat dengan menggunakan software Microsoft Excel berdasarkan data peramalan pasang surut yang diperoleh. Selanjutnya, membuat permodelan hidrodinamika 2D berdasarkan data arus, pasang surut dan batimetri dengan menggunakan software SMS (Sea water Modelling System) yang sesuai modul ADCIRC (Advanced Circulation Multi Dimansional Hydrodynamic Model). Hasil permodelan di verifikasi, yaitu membandingkan pola arus hasil model dengan pola arus hasil pengukuran lapangan.

\section{HASIL DAN PEMBAHASAN}

Data hasil penelitian konsentrasi klorofil-a yang diperoleh dari 8 stasiun di Perairan Muara Silugonggo disajikan pada Tabel 1.

Persebaran klorofil-a di perairan muara Sungai Silugonggo mempunyai pola mengarah dari wilayah muara ke wilayah laut. Berdasarkan waktu dan stasiun pengamatan menunjukkan, bahwa konsentrasi kandungan klorofil-a menyebar dan mengarah ke stasiun 4 (Gambar 1). Tingginya kandungan klorofil-a pada stasiun 4 dimungkinkan di wilayah tersebut terjadi akumulasi dari pergerakan massa air dan nutrien dari stasiun-stasiun lainnya. Hal ini dijelaskan oleh Rasyid (2009), bahwa suatu perairan mempunyai persebaran yang sangat spesifik karena merupakan hasil akumulasi dari berbagai faktor fisika, kimia dan biologi perairan serta kondisi dari perairan tersebut seperti garis pantai, koordinat geografis serta morfologi perairan. Dengan demikian persebaran yang terbentuk di stasiun penelitian menunjukkan, bahwa akumulasi yang terjadi yang merupakan tampilan dari berbagai faktor fisika, kimia, biologi dan geologi di wilayah tersebut.

Tabel 1. Hasil Analisis Kandungan Klorofil-a $\left(\mathrm{mg} / \mathrm{m}^{3}\right)$ di Perairan Muara Sungai Silugonggo, Pati

\begin{tabular}{|c|c|c|c|c|c|}
\hline $\begin{array}{c}\text { Stasiun } \\
\text { Pengamatan }\end{array}$ & 29 Maret 2015 & 12 April 2015 & 26 April 2015 & Rata-rata $(\bar{x})$ & $\begin{array}{c}\text { Simpangan } \\
\text { Baku (s) }\end{array}$ \\
\hline Stasiun 1 & 2,8967 & 1,2410 & 0,5046 & 1.5475 & 1.22 \\
\hline Stasiun 2 & 2,3166 & 1,6576 & 5,2802 & 3.0848 & 1.93 \\
\hline Stasiun 3 & 2,1191 & 1,3736 & 0,8558 & 1.4495 & 0.63 \\
\hline Stasiun 4 & 8,9724 & 12,1307 & 10,5647 & 10.5559 & 1.58 \\
\hline Stasiun 5 & 0,5731 & 5,0645 & 4,4218 & 3.3531 & 2.43 \\
\hline Stasiun 6 & 1,3290 & 1,8100 & 3,0404 & 2.0598 & 0.88 \\
\hline Stasiun 7 & 1,4992 & 2,1648 & 2,8716 & 2.1785 & 0.69 \\
\hline Stasiun 8 & 0,5724 & 0,4981 & 3,2603 & 1.4436 & 1.57 \\
\hline Rata-rata $(\bar{x})$ & 2,5348 & 3,2425 & 3,8499 & & \\
\hline $\begin{array}{c}\text { Simpangan } \\
\text { Baku (s) }\end{array}$ & 2,72 & 3,83 & 3,15 & & \\
\hline
\end{tabular}


Di samping itu, nilai kandungan klorofil-a yang tinggi pada stasiun 4 (Tabel 1) diduga terkait dengan lokasi penelitian yang terletak di kawasan vegetasi mangrove, daerah pertambakan dan berada dekat dengan muara Kali Langgen dan Kali Jaran. Kawasan vegetasi mangrove memberikan nutrien terbesar ke perairan. Serasah daun mangrove yang jatuh ke perairan akan mengalami dekomposisi sehingga dapat memberikan tambahan nutrien bagi pertumbuhan fitoplankton. Serasah tumbuhan mangrove juga merupakan sumber karbon dan nitrogen bagi hutan itu sendiri dan perairan sekitarnya (Indarto et. al., 1991). Selain itu, tingginya nilai klorofil-a di perairan diduga berasal dari tingginya kandungan nutrien yang berasal dari buangan limbah organik yang mengalir dari muara Kali Langgen dan Kali Jaran. Badan air Kali Langgen dan Kali Jaran digunakan sebagai saluran air pembuangan dari berbagai aktivitas manusia. Jenis kegiatan tersebut diantaranya limbah rumah tangga, area pertambakan dan kegiatan industri kecil. Kegiatan tersebut menghasilkan limbah buangan organik yang merupakan sumber dari bahan nutrien sebagai akibat dari degradasi yang dilakukan oleh mikroba. Rasyid (2009) menyatakan, bahwa suplai nutrien yang berasal dari daratan merupakan faktor utama yang mengakibatkan tingginya konsentrasi klorofil-a di perairan. Kandungan nutrien yang tinggi di perairan muara akan dimanfaatkan oleh fitoplankton untuk proses fotosintesis (Wenno, 2007). Selain itu, pengadukan air di daerah dangkal pada stasiun 4 dikarenakan adanya pertemuan air tawar dan air laut yang membawa nutrien dari daratan sehingga menyebabkan terjadinya pengkayaan nutrien dari dasar ke permukaan perairan. Dengan demikian adanya pengadukan air di daerah dangkal merupakan proses penting untuk mengembalikan zat-zat hara dari lapisan dasar ke lapisan permukaan sehingga dapat digunakan dalam proses fotosintesis.

Nilai klorofil-a terendah terjadi di stasiun 8 (29 Maret dan 12 April), dan stasiun 1 (26 April). Rendahnya nilai kandungan klorofil-a di stasiun 8 diduga karena pergerakan arus surut menuju pasang memiliki dominan arah arus yang berasal dari laut dalam menuju darat. Pergerakan arus laut sangat berpengaruh pada persebaran klorofil-a di perairan. Ditambahkan oleh Rasyid (2009), bahwa sebaran klorofil-a lebih rendah konsentrasinya pada perairan lepas pantai dikarenakan tidak adanya suplai nutrien dari daratan secara langsung. Pada stasiun 1 (pengambilan sampel ketiga, 26 April) memiliki nilai kandungan klorofil-a yang rendah. Hal ini ditunjukkan pada saat penelitian kondisi perairan muara Sungai Silugonggo sangat keruh. Keruhnya perairan disebabkan oleh adanya partikel-partikel tersuspensi dan tingkat endapan lumpur yang tinggi yang dibawa dari daratan dan muara kali yang berada di sekitar perairan. Dengan demikian nilai klorofil-a yang rendah pada ketiga stasiun ini erat kaitannya dengan massa air, pasang surut dan arus yang ditimbulkannya, serta kedalaman perairan yang mempengaruhi.

Tinggi dan rendahnya kandungan klorofil-a dipengaruhi oleh parameter kualitas perairan yang mendukung kehidupan fitoplankton di perairan. Nilai suhu permukaan di stasiun 4 relatif tinggi sebesar $33,1^{\circ} \mathrm{C}$ dan nilai suhu di stasiun 8 relatif rendah sebesar $31,7^{\circ} \mathrm{C}$. Pengaruh suhu terhadap fitoplankton adalah dapat meningkatkan reaksi kimia sehingga laju fotosintesis meningkat seiring dengan kenaikan suhu. Hal ini sesuai yang dinyatakan Simanjuntak (2009), bahwa semakin tinggi suhu di perairan akan mengakibatkan peningkatan laju fotosintesis hingga mencapai maksimum. Ditambahkan oleh Prianto et. al. (2013), suhu mengalami perubahan secara perlahan-lahan dari daerah pantai menuju laut lepas. Umumnya suhu di pantai lebih tinggi dari daerah laut karena daratan lebih mudah menyerap panas matahari dibandingkan dengan perairan laut. Nilai salinitas yang terukur di stasiun 4 cukup rendah, dikarenakan stasiun 4 berada di muara perairan yang mendapat pengaruh dari aliran sungai sehingga terjadi pengenceran. Nilai salinitas di stasiun 8 cukup tinggi, karena berada jauh dari daratan. Menurut Azis (2007), semakin banyak sungai yang bermuara ke laut tersebut maka salinitas laut akan rendah dan sebaliknya makin sedikitnya sungai yang bermuara ke laut tersebut maka salinitas akan tinggi. Variasi salinitas dapat menentukan kelimpahan dan distribusi fitoplankton dalam suatu perairan. Di perairan pantai yang bersalinitas rendah komunitas fitoplankton lebih tinggi daripada perairan yang jauh dari pantai (Simanjuntak, 2009). Derajat keasaman $(\mathrm{pH})$ perairan yang baik untuk pertumbuhan organisme air berkisar antara $6,5-8,5$. Secara keseluruhan nilai $\mathrm{pH}$ perairan rendah mendekati pesisir dan cenderung meningkat mendekati perairan laut. Rendahnya $\mathrm{pH}$ pada daerah pesisir diduga karena pengaruh masukan air tawar yang banyak membawa zat-zat organik, yang kemudian akan mengalami 
pembusukan yang dapat mempengaruhi nilai $\mathrm{pH}$ (Simanjuntak, 2009). Kandungan $\mathrm{pH}$ di stasiun 4 dan di stasiun 8 masih berada ada kisaran tersebut sehingga masih baik untuk kehidupan organisme. Kandungan oksigen terlarut $(\mathrm{DO}=$ dissolved oxygen) di stasiun 4 sebesar $7,15 \mathrm{mg} / \mathrm{l}$ masih termasuk dalam kisaran baku mutu Keputusan MENLH No. 51 Tahun 2004, yaitu >5 mg/l dan kandungan DO di stasiun 8 relatif rendah sebesar $4,20 \mathrm{mg} / \mathrm{l}$. Nilai ini sesuai dengan tingkat kelimpahan klorofil-a pada tiap stasiun penelitian. Kelimpahan klorofil-a yang tinggi akan menghasilkan oksigen yang lebih banyak dibandingkan. Oksigen terlarut merupakan salah satu hasil produksi dari proses fotosintesis (Haryadi et. al., 2012). Nilai kecerahan di stasiun 4 relatif rendah dibandingkan dengan stasiun 8 . Menurut Effendi (2003), kecerahan perairan akan menurun bila mendekati pantai dan meningkat bila menjauhi pantai. Hal ini dipengaruhi oleh adanya hasil dari berbagai aktivitas di sepanjang sungai seperti adanya partikel-partikel daratan (lumpur, pasir, bahan-bahan organik) yang terbawa masuk ke perairan laut. Dengan demikian parameter kualitas perairan yang didapatkan dari hasil pengukuran tergolong menunjang produktivitas perairan di wilayah perairan muara Sungai Silugonggo.

\section{Kandungan Klorofil-a Terkait Arus Surut Menuju Pasang, Kandungan Nitrat dan Ortofosfat di Perairan Muara Sungai Silugonggo}

Berdasarkan waktu pengambilan sampel, nutrien (nitrat dan ortofosfat) menunjukkan hasil sebaran yang cukup beragam Hal ini dipengaruhi oleh arus surut menuju pasang dari arah timur laut $\left(45^{\circ}\right)$ ke arah barat daya $\left(225^{\circ}\right)$ dengan kecepatan berkisar $0,03-0,15 \mathrm{~m} /$ det. Hasil penelitian menunjukkan bahwa stasiun 1,2,3 dan 4 memiliki kandungan klorofil-a yang tinggi (Tabel 1) dan di dukung dengan kandungan nutrien yang tinggi pula. Pada stasiun tersebut persebarannya cukup merata dan memiliki kekuatan arus yang relatif kecil. Kandungan klorofil-a di stasiun 5 relatif tinggi dengan sirkulasi arus yang relatif tinggi pula. Stasiun 6,7 dan 8 memiliki kandungan klorofil-a yang rendah dengan pergerakan arus yang tinggi. Hal ini disebabkan karena pengaruh yang kuat dari faktor fisika yaitu arus surut menuju pasang. Menurut Pratama et. al. (2012), pasang surut mengakibatkan fluktuasi muka air laut di perairan yang berpengaruh terhadap massa air laut dan kandungan zat yang ada di perairan. Oleh karena itu, persebaran klorofil-a pada penelitian ini dipengaruhi oleh parameter fisika berupa arus surut menuju pasang.

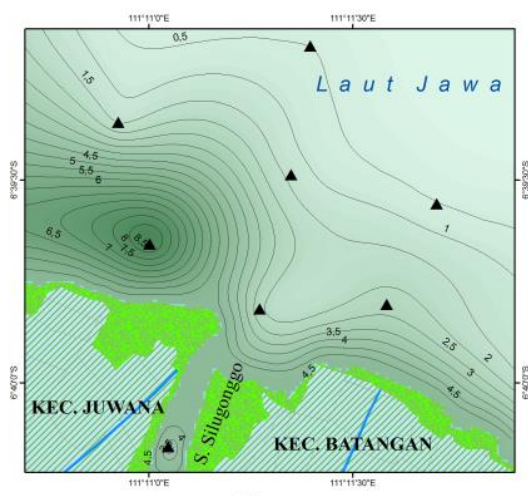

(a)

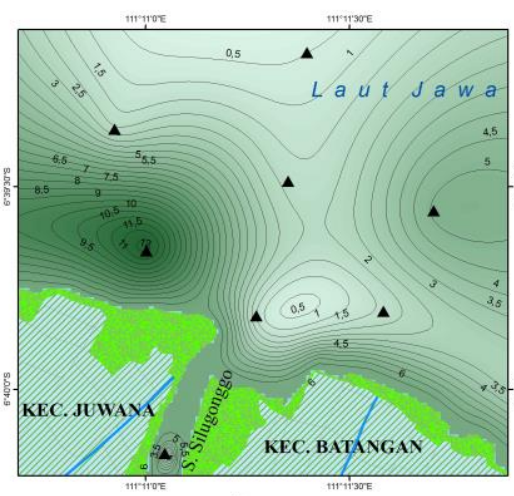

(b)

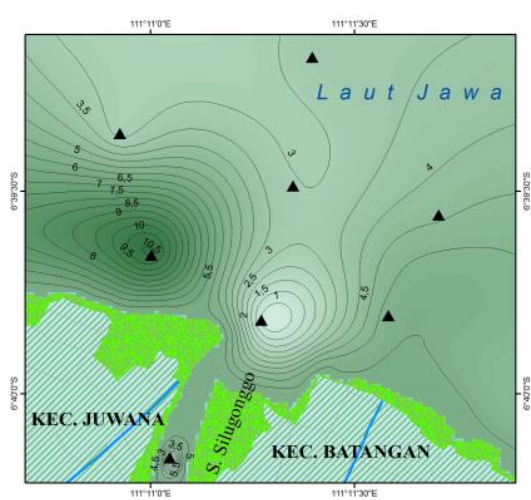

(c)

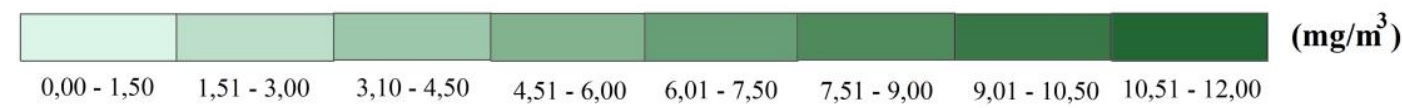

Legenda

\ Titik Penelitian

Tambak

Gambar 1. Sebaran Klorofil-a Secara Horizontal di Perairan Muara Sungai Silugonggo. (a) Pengukuran klorofil-a 29 Maret 2015 (b) Pengukuran klorofil-a 12 April 2015 (c) Pengukuran klorofil-a 26 April 2015. Sumber: Peta Lingkungan Perairan Indonesia Jawa Tengah Skala 1:500000 Publikasi Dishidros TNI-AL Tahun 2004. Peta Rupa Bumi Indonesia Lembar 1509-132 Skala 1:25000 Publikasi Bakosurtanal Tahun 1999. Survey Lapangan di Muara Sungai Silugonggo Kabupaten Pati Bulan Maret-April Tahun 2015. 


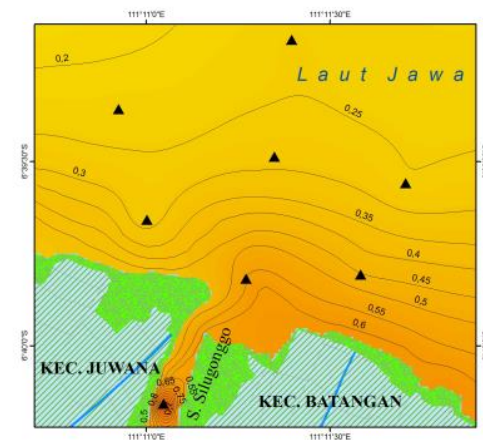

(a)

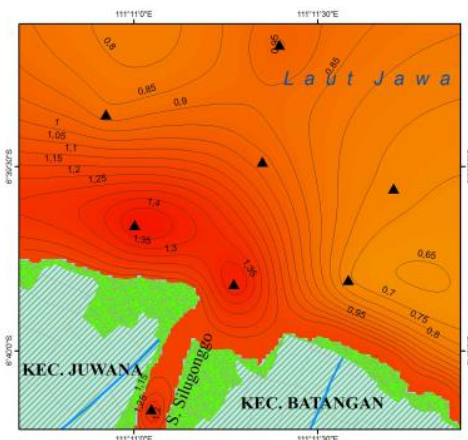

(b)

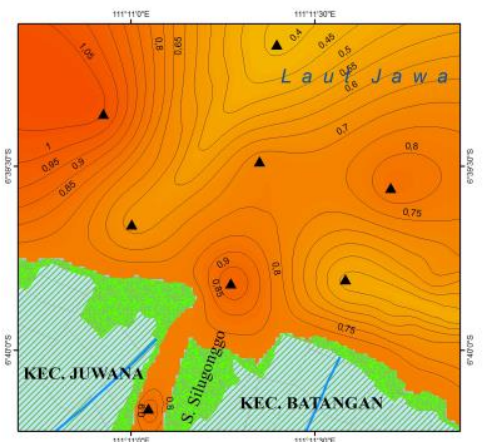

(c)

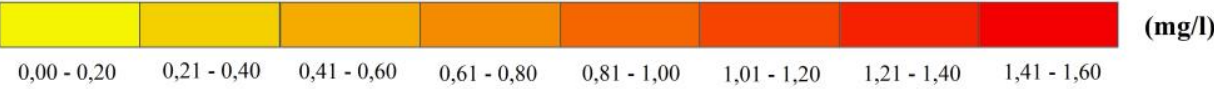

Legenda

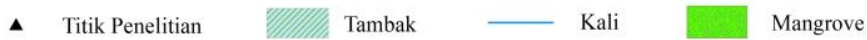

Gambar 2. Sebaran Nitrat Secara Horizontal di Perairan Muara Sungai Silugonggo. (a) Pengukuran nitrat 29 Maret 2015 (b) Pengukuran nitrat 12 April 2015 (c) Pengukuran nitrat 26 April 2015. Sumber: Peta Lingkungan Perairan Indonesia Jawa Tengah Skala 1:500000 Publikasi Dishidros TNI-AL Tahun 2004. Peta Rupa Bumi Indonesia Lembar 1509-132 Skala 1:25000 Publikasi Bakosurtanal Tahun 1999. Survey Lapangan di Muara Sungai Silugonggo Kabupaten Pati Bulan Maret-April Tahun 2015.

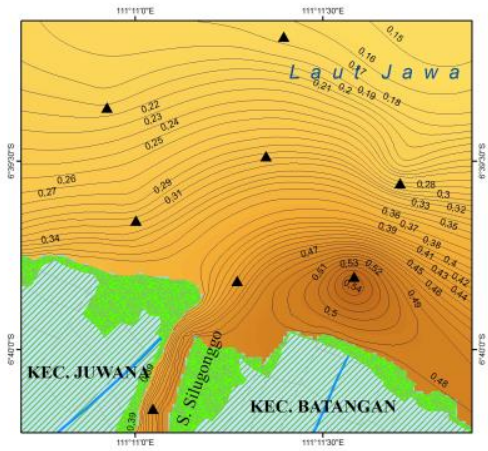

(a)

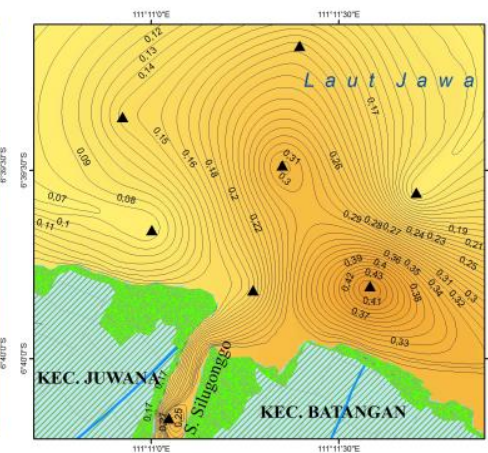

(b)

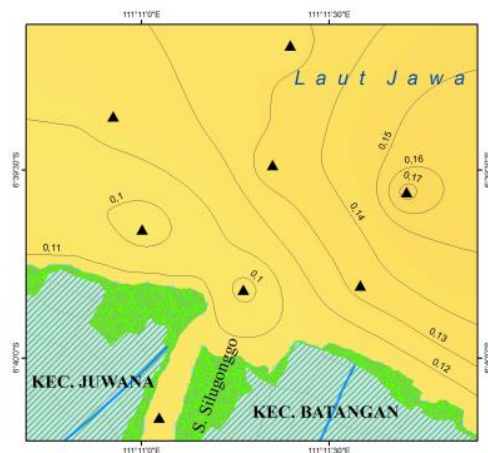

(c)

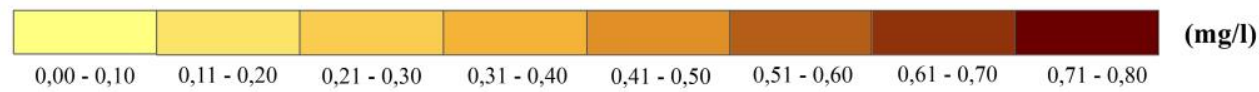

Legenda

- Titik Penelitian

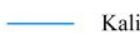

Mangrove

Gambar 3. Sebaran Fosfat Secara Horizontal di Perairan Muara Sungai Silugonggo. (a) Pengukuran ortofosfat 29 Maret 2015 (b) Pengukuran ortofosfat 12 April 2015 (c) Pengukuran ortofosfat 26 April 2015. Sumber: Peta Lingkungan Perairan Indonesia Jawa Tengah Skala 1:500000 Publikasi Dishidros TNI-AL Tahun 2004. Peta Rupa Bumi Indonesia Lembar 1509-132 Skala 1:25000 Publikasi Bakosurtanal Tahun 1999. Survey Lapangan di Muara Sungai Silugonggo Kabupaten Pati Bulan Maret-April Tahun 2015.

Sebaran konsentrasi klorofil-a dan nutrien berdasarkan hasil pengamatan menunjukkan bahwa pada stasiun $1,2,3$ dan 4 memiliki kandungan klorofil-a yang tinggi dan begitu pula dengan kandungan nutrien yang cukup tinggi. Hal ini menunjukkan bahwa proses fotosintesis berjalan dengan baik, karena sebaran klorofil-a yang merata dan didukung dengan pergerakan arus yang cukup rendah. Pada stasiun 6,7 dan 8 memiliki nilai kandungan klorofil yang rendah dengan kandungan nutrien yang relatif rendah pula. Hasil pengukuran data nutrien menunjukkan nilai kandungan yang sesuai dengan kadar optimum untuk proses fotosintesis. Hal ini sesuai yang dinyatakan Sanusi (2004), yaitu kadar optimum untuk proses fotosintesis adalah 0,9 - 


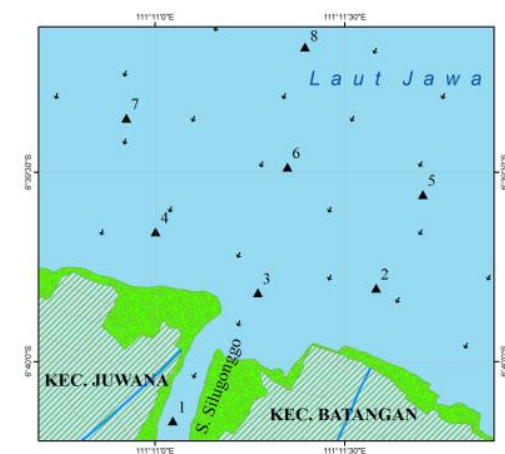

(a)

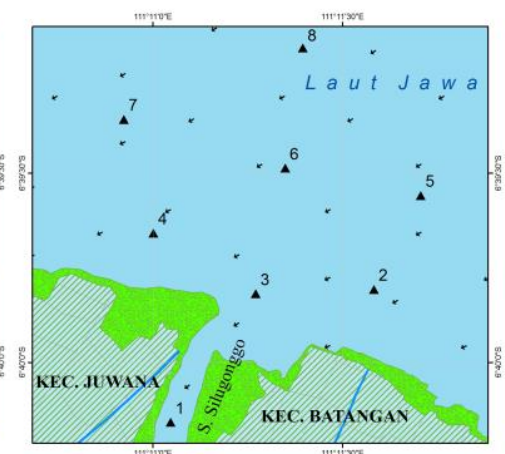

(b)

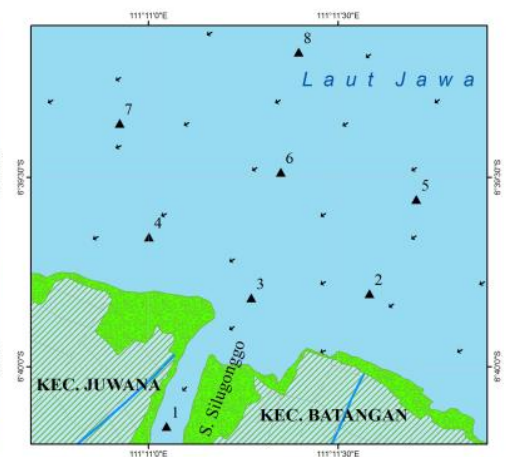

(c)

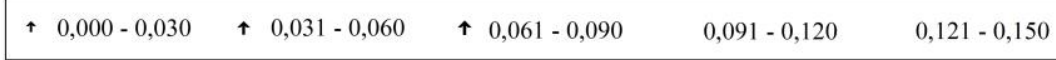

$(\mathbf{m} / \mathbf{s})$

\section{Legenda}

- Titik Penelitian

Mangrove

Gambar 4. Simulasi Model Arus Ketika Surut Menuju Pasang di Perairan Muara Sungai Silugonggo. (a) Pengukuran arus 29 Maret 2015 (b) Pengukuran arus 12 April 2015 (c) Pengukuran arus 26 April 2015. Sumber: Peta Lingkungan Perairan Indonesia Jawa Tengah Skala 1:500000 Publikasi Dishidros TNI-AL Tahun 2004. Peta Rupa Bumi Indonesia Lembar 1509-132 Skala 1:25000 Publikasi Bakosurtanal Tahun 1999. Survey Lapangan di Muara Sungai Silugonggo Kabupaten Pati Bulan Maret-April Tahun 2015.

$3,5 \mathrm{mg} / \mathrm{l}$ untuk nitrat dan $0,09-1,80 \mathrm{mg} / \mathrm{l}$ untuk ortofosfat. Senyawa nitrat, fosfat, amonium, dan silikat merupakan zat hara penting yang diperlukan dalam proses fotosintesis. Dengan demikian sebaran klorofil-a juga dipengaruhi oleh faktor kimia yaitu nutrien (nitrat dan ortofosfat).

\section{SIMPULAN}

Berdasarkan dari hasil penelitian didapatkan, bahwa nilai kandungan klorofil-a yang terdapat di perairan muara Sungai Silugonggo berkisar antara 0,4981 - 12,1307 $\mathrm{mg} / \mathrm{m}^{3}$. Nilai kandungan klorofil-a secara horizontal di Perairan Muara Sungai Silugonggo lebih dipengaruhi oleh masukan dari sungai, vegetasi mangrove dan daerah pertambakan. Sebaran klorofil-a secara horizontal memiliki pola mengarah dari wilayah muara sungai ke arah laut. Persebaran klorofil-a secara horizontal di perairan muara Sungai Silugonggo dominan dipengaruhi oleh arus dengan pola mengarah dari timur laut $\left(45^{\circ}\right) \mathrm{ke}$ arah barat daya $\left(225^{\circ}\right)$ dengan kecepatan berkisar $0,03-0,15 \mathrm{~m} /$ det.

\section{DAFTAR PUSTAKA}

Azis, M. F. 2007. Tipe Estuari Binuangeun (Banten) Berdasarkan Distribusi Suhu dan Salinitas Perairan. Oseanologi dan Limnologi di Indonesia., Vol.33:97-110.
Damaianto, B. dan A. Masduqi. 2014. Indeks Pencemaran Air Laut Pantai Utara Kabupaten Tuban dengan Parameter Logam. Jurnal Teknik Pomits., 3(1):1-4.

Effendi, H. 2003. Telaah Kualitas Air. PT. Kanisius, Yogyakarta,161hlm.

Haryadi, J. dan Hadiyanto. 2012. Korelasi Nutrien Terlarut dengan Struktur Komunitas Plankton di Tambak Mangrove Blanakan, Kab. Subang. Jurnal Pengelolaan Sumber Daya Alam dan Lingkungan., 2(2):73-84.

Indarto, Y., Suhardjono dan Mulyadi. 1991. Pola Variasi Produksi Serasah Hutan Mangrove Pulau Dua, Jawa Barat. Dalam: Prosiding Seminar IV Ekosistem Mangrove di Bandar Lampung Tanggal 7 Agustus 1990. Jakarta, 169-174p.

Pratama, T. R., E. Indrayanti dan I. B. Prasetyawan. 2012. Kajian Pola Arus dan Co-Range Pasang Surut di Teluk Benete Sumbawa NusaTenggara Barat. Journal of Oceanography., 1(1):111-120.

Prianto, T. Z. Ulqodry dan R. Aryawati. 2013. Pola Sebaran Konsentrasi Klorofil-a di Selat Bangka dengan Menggunakan Citra AquaModis. Jurnal Maspari., 5(1):22-33. 
Rasyid, A. 2009. DistribusiKlorofil-a Pada Musim Peralihan Barat-Timur di Perairan Spermonde Proponsi Sulawesi Selatan. J. Sains \& Teknologi., 9(2):125-132.

Riyono, S. H. 2006. Beberapa Metode pengukuran Klorofil Fitoplankton di Laut. Jurnal Oseana., 31(3):33-44.

Sanusi, H. S. 2004. Karakteristik Kimiawi dan Kesuburan Perairan Teluk Pelabuhan Ratu Pada Musim Barat dan Timur. Jurnal IlmuIlmu Perairan dan Perikanan Indonesia., 11(2):93-100.

Saraswati, A. A. 2004. Konsep Pengelolaan Ekosistem Pesisir (Studi Kasus Kecamatan Ulujami, Kabupaten Pemalang, Jawa Tengah). J. Tek. Ling., 5(3): 205-211.
Simanjuntak, M. 2009. Hubungan Faktor Lingkungan Kimia, Fisika Terhadap Distribusi Plankton di Perairan Belitung Timur, Bangka Belitung. Jurnal Perikanan., 11(1):31-45.

Sugiyono. 2014. Metode Penelitian Kuntitatif, Kualitatif dan R\&D. Alfabeta. Bandung, 334hlm.

Wenno, L. F. 2007. Biodiversitas Organisme Planktonik dalam Kaitannya dengan Kualitas Perairan dan Sirkulasi Massa Air di Selat Makassar. Pusat Penelitian Oseanografi (LIPI). Jakarta, 28hlm.

Zainuri, M. 2010. Kontribusi Sumberdaya Fitoplankton Terhadap Produktivitas dan Keseimbangan Ekosistem dalam Pengelolaan Wilayah Pesisir. Pengukuhan Guru Besar, Semarang, 68hlm. 